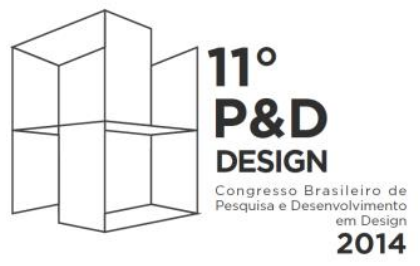

Gramado - RS

\title{
DO DESENHO DE CRIANÇA À ILUSTRAÇÃO INFANTIL.
}

\author{
José Salmo Dansa de Alencar \\ Pontifícia Universidade Católica do Rio de Janeiro - PUC Rio \\ salmo.dansa@gmail.com
}

Resumo: A proposta deste artigo é estabelecer relações entre as gêneses do desenho feito por crianças e da ilustração feita para crianças, partindo de um esquema descritivo da morfologia e do processo criativo do desenho infantil e, através deste referencial teórico, tentar expor uma análise de aspectos estéticos de cada um desses tipos de imagem. $O$ trabalho descreve as etapas da maturação e aspectos morfológicos da mudança da linguagem visual (ícone gráfico) para linguagem verbal escrita (símbolo gráfico); aponta afinidades ontológicas e relações cíclicas de influência entre o desenho infantil e a ilustração de livros infantis; e estabelece relações poéticas sublinhando a importância da memória no processo criativo das duas formas de expressão gráfica.

Palavras-Chave: Processo criativo, Análise estética, Desenho de criança, ilustração de livros.

Abstract: The purpose of this article is to establish relationships between the genesis of the drawing made by children and illustration made for children, starting from a descriptive scheme of the morphology and the creative process of children's drawing and, through this theoretical framework, trying to expose an analysis of aesthetic aspects each of these image types. The work describes the stages of maturation and morphological aspects of the change of visual language (graphical icon) to the written verbal language (graphic symbol); points out ontological affinities and cyclical relations of influence between child drawing and illustration of children's books; and establishes poetic relations stressing the importance of memory in the creative process of two forms of graphic expression.

Keywords: Creative process, Aesthetic analysis, Child drawing, Book illustration. 


\section{INTRODUÇÃO}

Este trabalho tem como pano de fundo a pesquisa de mestrado concluída em $2004^{1}$ e a pesquisa de doutorado iniciada em março de 2014, ambas pela PUC-Rio, que versavam sobre os dois objetos deste estudo, respectivamente: o desenho de criança e a ilustração infantil.

As bases teóricas utilizadas foram os estudos do desenvolvimento da criança de Jean Piaget (1968) os estudos sobre as 'imagens iniciais' (desenho infantil) de Bernard Darras (1996), noções sobre o imaginário de Gilbert Durand (1994) e conceitos sobre imagens em Vilém Flusser $(1985,2007)$. As poéticas de Gaston Bachelard $(2008,2009)$ fundamentam a busca por relações entre esses dois tipos de imagens. Assim, esta abordagem se baseia no conhecimento empírico ${ }^{2}$ e nos conceitos sobre a imagem elaborados por esses autores, mas é movida principalmente pelos "devaneios voltados para infância" ${ }^{3}$. O objetivo central é descrever os aspectos de uma relação cíclica de caráter estético e comunicativo para averiguar interseções poéticas entre essas duas vertentes da linguagem do desenho.

O trabalho parte de uma apresentação do problema e da metodologia relacionada ao referencial teórico e três blocos de desenvolvimento. $O$ primeiro bloco consiste em alguns fundamentos da psicogênese do desenho infantil, descrição dos sinais gráficos relacionados às fases de desenvolvimento da criança e apontamento de semelhanças entre os dois processos criativos. $O$ segundo bloco descreve o momento onde a criança 'escolhe' abandonar ou preservar a linguagem do desenho e aponta origens ontológicas das imagens da literatura infantil. O terceiro bloco aborda o aspecto poético e a relação cíclica entre os dois tipos de imagem, onde o ilustrador é movido pela memória em busca de identificação com seu público.

\section{DESENVOLVIMENTO}

O que une esses dois tipos de imagem como objetos neste estudo é uma relação de espelhamento que traz a criança como sujeito, mas em posições invertidas em relação a cada uma delas, ou seja, ela é autora no caso dos desenhos e é público no caso das ilustrações.

Por outro lado, a maior oposição conceitual entre essas imagens pode ser atribuída à distinção entre imagem artesanal e imagem técnica apresentada de Vilém Flusser ${ }^{4}$. 0 desenho de criança é imagem essencialmente artesanal, pois não é mediada por nenhum aparelho, enquanto a ilustração de livros infantis, mesmo quando é produzida artesanalmente, se torna imagem técnica no processo de editoração.

\footnotetext{
${ }^{1}$ Alencar, J. Salmo Dansa de. O começo é o fim pelo avesso: a transposição da narrativa oral para o desenho infantil - 95 f. Dissertação (mestrado): Departamento de Artes e Design - Pontifícia Universidade Católica do Rio de Janeiro. Rio de Janeiro, 2004.

${ }^{2} \mathrm{O}$ autor se refere aqui ao citado trabalho de campo de sua referida pesquisa de mestrado e também à sua atuação por mais de 20 anos como autor e ilustrador de livros infantis e juvenis, com mais de 80 livros publicados.

${ }^{3}$ BACHELARD, Gaston. Poética do devaneio São Paulo: Martins Fontes, 2009. P. 93.

${ }^{4}$ FLUSSER, Vilém. Filosofia da Caixa Preta. Rio de Janeiro: Relume Dumara, 2002. P. 14.
} 
Nesse sentido, este artigo busca responder o seguinte problema: De que forma as relações de oposição e complementaridade se manifestam nessas imagens e que tipo de interseções podem existir entre seus processos criativos?

A metodologia de análise utilizada nos estudos anteriores se baseava na fenomenologia das imagens. O primeiro estudo estava relacionado ao desenho como fruto de uma transposição e seus aspectos criativos, narrativos e mnemônicos, tomando a criança como sujeito da atividade de desenhar e 'ilustrar' histórias. 0 trabalho abrangia o reconto de narrativas de pessoas idosas para alunos de escolas do Rio de Janeiro para que eles desenhassem algo sobre essas histórias, resultando na produção e posterior análise de cerca 450 desenhos. O objetivo era observar a transposição de linguagens, além de: (1) a memória da narrativa oral; (2) o processo criativo; e (3) o potencial narrativo dos desenhos infantis.

O segundo estudo é a pesquisa de doutorado iniciada em 2014 que abrange as imagens bibliográficas voltadas para a infância. Esse estudo teve como base a pesquisa realizada em 2008 através de uma bolsa de residência concedida pela Internationale Jugendbibliothek München - $I J B^{5}$ onde o tema era $A$ narrativa visual nos livros sem texto. A pesquisa teve como objetivo a análise morfológica de um acervo internacional com mais de 600 livros infantis.

Assim, o principal ponto em comum entre os objetos deste estudo é a criança, tomada no caso dos desenhos como autora e no segundo caso como público. Essa diferença de posições da criança em relação às imagens sugere um compartilhamento do imaginário, entendido aqui como as 'representações do pensamento' tanto na criação quanto na fruição.

Gilbert Durand afirma que "Todo pensamento humano é uma representação, isto é, passa por articulações simbólicas" ${ }^{6}$. Em seu livro sobre o imaginário, o autor aborda a dualidade como tema pertinente ao estudo das imagens, lembrando que, "todo 'objeto' imaginário é constitutivamente 'dilemático' (Claude Levi-strauss) ou 'anfibológico' (isto é, 'ambíguo' ao compartilhar com seu oposto uma qualidade comum)." 7

Durand atribui a Gaston Bachelard a origem dessa possível coerência entre plurais no estudo do imaginário e a possibilidade de diálogo entre imagens aparentemente opostas ou polarizantes. Este trabalho se vale da abordagem fenomenológica das poéticas bachelardianas para se referir às 'imagens bibliográficas' e às 'imagens iniciais' em busca de relações processuais e poéticas.

De imediato, vale diferenciar e ressaltar dois aspectos interdependentes do que podemos compreender como conceito de imagem. Existe, uma imagem mental que tende a ser parte ou um estágio do desenho, e outra que é uma imagem configurada no espaço bidimensional do papel, uma tela de pintura ou a superfície plana de um computador. Quando se fala da imagem como ilustração de textos ou das ideias que cercam o processo criativo do ilustrador, a diferença entre ambos os conceitos tende a aumentar, embora a intimidade entre eles se faça inextrincável. Explico: um texto a ser

\footnotetext{
${ }^{5}$ A Internationale Jugendbibliothek München - IJB tem o maior acervo de livros infantis e juvenis do mundo e concede anualmente até 10 bolsas para residências de 3 meses para especialistas e autores de literatura infantil. A pesquisa resultou em uma lista cronológica de 613 livros (aproveitada pela biblioteca) além de 170 resenhas e fotos das principais publicações entre 1823 e 1999.

${ }^{6}$ DURAND, Gilbert. O imaginário. Rio de Janeiro: Difel, 1994. P.41.

${ }^{7}$ Ibidem. P. 84.
} 
ilustrado necessariamente suscita imagens mentais que vão se configurando, através de esboços ou rascunhos, tentativas que levam a novas imagens - e esse é o ponto em comum com o desenho de uma criança: a imaginação contínua, o ato de imaginar e formular imagens mentalmente sem dissociá-las da ação desenho. É essa concomitância entre o traço e o pensamento que permite ao desenho ser um modo de conceber, quanto construir e expressar ideias.

\subsection{Gênese e desenvolvimento do desenho infantil}

Para se entender a psicogênese do desenho infantil, é preciso ter em conta que ele está na origem da ilustração ou qualquer outra expressão estética que possui o desenho como base. $O$ desenho é uma expressão cultural que traz em si determinados aspectos epigenéticos, ou seja, carrega informações a respeito de sua gênese, do modo e da própria ação de representar o mundo real ou psíquico-imaginário de cada criança ou artista já adulto. O desenho liga-se diretamente ao desenvolvimento psicomotor do sujeito, desde muito cedo, e Gilbert Durand afirma que a lenta maturação do cérebro permite ao meio social desempenhar um papel importante nos processos desse aprendizado. Ele sustenta que "a articulação simbólica somente se manifesta por volta dos quatro ou cinco anos. A formação anatômica do cérebro humano se encerra por volta dos sete anos, e as reações encefalográficas se normalizam aos vinte anos". ${ }^{8}$

Resumidamente, a similitude entre os desenhos e o desenvolvimento cerebral torna-se evidente pela fala da criança que os fez. Uma criança pequena desenha e, ao fim, nomeia as figuras e dá título ao desenho. A criança um pouco mais velha dá nome a seu desenho quando já está quase pronto e, mais adiante, saberá de antemão o que deseja desenhar.

Logo nos primeiros estágios, o desenho vem acompanhado da fala egocêntrica da criança. Tal qual reconheceu Jean Piaget, o desenho é parte de uma expressão polifônica e não poderia ser visto separadamente, como uma simples expressão gráfica; o desenho infantil integra uma rede particular de descrições, onomatopeias, expressões faciais e gestos. Por isso, devemos evitar a tradicional dissociação entre vetores linguísticos, gestuais e gráficos, porque não estamos face à obras estáticas e fechadas, mas em meio a um conjunto comunicacional bastante dinâmico. Assegura o estudioso suíço: "Um desenho, cortado da 'polifonia' de seu meio gestual, postural, oral, verbal e social, é só um vestígio de um conjunto comunicacional coordenado". ${ }^{9}$

Outro fator importante é o aspecto social do desenho. Isto pode ser observado no modo cooperativo de sua produção quando existe um grupo de crianças, como acontece na sala de aula e no ambiente familiar. Nesses momentos, são naturais as constantes colaborações, imitações, trocas, modificações de certos elementos do desenho, das cores, dos ícones, etc.. O que passa a contar é o aspecto das trocas plurimídias: a força comunicativa do desenho. Entre seus colegas, amigos, irmãos, o desenho para a criança é a possibilidade de um jogo comunicativo que se estabelece através de imagens mais ou menos convencionais, desenhos que seguem um padrão

\footnotetext{
${ }^{8}$ DURAND, Gilbert. 1994. P.45. Op. Cit.

${ }^{9}$ PIAGET, J.; INHELDER, B. 1968. Op. Cit.
} 
de representação adequado a um determinado modelo. Exemplo praticamente universal são as casas com telhados triangulares e chaminé, porta e janela, ou o sol na forma de um círculo e uma sequência de linhas ao redor representando raios.

Com estas primeiras fases do desenvolvimento infantil, o grafismo já busca uma forma de entendimento nas organizações icônicas. Inicialmente, reconhecemos os ícones de gesto, aqueles riscos ou traços que às vezes se manifestam antes de um ano de idade. São modulações de segmentos, circunvoluções de linhas que levam à emergência dos ícones de ritmo. Combinando os traços e controle do ritmo, chega-se às formas regulares nos experimentos da criança com lápis, crayon ou canetas hidrográficas sobre o papel. Em seguida, ela passa a explorar os chamados ícones de ações, derivados e complementares aos jogos que se desenvolveram com os materiais de desenho sobre a folha. Um caminhão de bombeiros, um avião ou um animal mesmo que imaginário deixam rastros atrás de si que organizados como ícones de ação, muito análogos àqueles traços que indicam movimento nas histórias em quadrinhos.

Desta maneira, a exploração de semelhanças e analogias com o mundo guiará a criança na direção das imagens de objetos e figuras. Avidamente, a sociedade espera, encoraja e felicita este evento. Paralelamente, a denominação verbal se impõe no mosaico plurimídia dos desenhos, assumindo um papel identificador e orientando o reconhecimento dos atributos pertinentes às imagens de objetos e figuras.

Desde os sete até os dez anos, a criança está apta a fazer do desenho uma prática complexa, resultante do percurso de fases anteriores. Ela já sabe desenhar, é mestra do seu sistema de representação e revela, em última análise, um prazer em compartilhar seu domínio comunicativo e estético. O repertório visual e a articulação do discurso gráfico fazem com que o conceito de "novato" seja um tanto inadequado a criança nessa etapa. Ela se encontra no ápice do desenvolvimento de seu potencial criativo! Certamente, a maior parte dos adultos não desenhará tanto, nem com tanta frequência, muito menos irá se desenvolver, como nessa fase da criança.

Porém, nesse momento, tornam-se mais nítidas duas influências que polarizam as intenções do ato de desenhar. De um lado, temos o aspecto genérico que imprime às formas originais uma inclinação mais comunicativa e, de outro, o aspecto singular, que acabará por moldar o traço e a caligrafia da criança como uma representação única. Este é o ponto alto do desenvolvimento do desenho infantil e assinala uma mudança radical na representação gráfica. É quando a evolução do traço tende a se estabilizar para a maioria dos indivíduos.

Bem próximas aos dez anos, as crianças sentem grande atração por desenhos com características realistas. Os estudos demonstram que justamente nesse período uma grande maioria deixa de desenhar, interrompendo o desenvolvimento de sua capacidade de expressão e representação gráfica. Isso ocorre porque, como afirma Beth Edwards, "a aptidão para o desenho não é vital para a sobrevivência na cultura em que vivemos, como são a fala e a leitura" ${ }^{10}$ É comum muitas crianças deixarem de desenhar nesse momento, enquanto muitos adultos permaneçam neste estágio, ou seja, desenhando como crianças. Existe uma conceituação dos desenhos (ícones gráficos) que progressivamente são substituídos pela palavra escrita (símbolos gráficos).

${ }^{10}$ EDWARDS, Beth. Desenhando com o lado direito do cérebro. Rio de Janeiro: Ediouro. 2000. 
Importante ressaltar: os primeiros traços de uma criança parecem resultar unicamente de sua ação, e não de uma intenção, sendo produzidos a partir da motricidade física e da imitação de gestos, para adquirirem pouco a pouco algum significado. Os significados da imagem emergem de níveis mais complexos de elaboração, à medida que a criança passou a nomear personagens, lugares, ações. A própria sucessão dessas representações impõe narratividade às imagens e, com o tempo, vai sendo estabelecida uma sincronia entre o desenho gráfico e a verbalização da imagem. Conforme o domínio é adquirido, a criança que desenha permite-se anunciar o que pretende fazer; esse estágio coincide com as necessidades de maior desenvolvimento verbal, quando as intenções e o gosto por desenhos 'realistas' tendem a superar suas habilidades. Podemos afirmar, por fim, que a atividade estética da criança conseguirá atravessar essa fase e sobreviver na vida adulta, quando a singularidade de seus desenhos for valorizada frente à generalidade representada pelas palavras.

Não restam dúvidas: a tendência em privilegiar a expressão verbal aponta para nossa necessidade de comunicação. No entanto, para as novas gerações em um mundo informatizado, as interfaces digitais interativas mostram que a imagem guarda ampla potência comunicativa - e que os adultos, sobretudo designers, professores, ilustradores, escritores, mediadores de leitura reencontram o desenho na parte mais essencial das novas modalidades de comunicação.

\subsection{As imagens da infância e as imagens da literatura}

A criança tem um mundo próprio, bem diferente de nós adultos. Elas, assim como os idosos, não estão inseridas nas necessidades produtivas da sociedade e, de alguma maneira, são representantes de uma relação complementar entre imaginação e memória. Bachelard afirma que essa é uma relação indissolúvel e "a tripla ligação imaginação, memória e poesia deverá (...) ajudar-nos a situar, no reino dos valores, esse fenômeno humano que é uma infância solitária, uma infância cósmica" ${ }^{11}$ Torna-se importante ressaltar que os desenhos colaborativos, feitos entre colegas em suas trocas plurimídias, já não existem na fase posterior aos dez anos. A atividade do desenho tende a ser uma construção solitária: a criança e suas primeiras obras precisam sobreviver ao vazio e à falta de interlocutores, encontrar significado em si próprias. O mundo interno precisa se impor ao externo, pois mesmo se alimentando das imagens do mundo visível ao campo da percepção, o desenho nasce de uma necessidade que abre mão da interação e da comunicação em função de um prazer expressivo e estético.

Ora, a memória da infância traz consigo diferenças em relação ao nosso mundo real. Como diz Bachelar: "Lembramo-nos enquanto sonhamos, sonhamos enquanto nos lembramos". O mundo do devaneio da infância é grande, maior que o mundo oferecido ao devaneio nas fases da adolescência e idade adulta. Gulliver, Alice, Narizinho, muitas são as imagens miniaturizadas ou imagens de miniaturas que enfatizam imensidades, desde Charles Perrault, os Irmãos Grimm, Andersen e todas as decorrências na literatura infantil contemporânea.

${ }^{11}$ BACHELARD. Gaston. 2009. P.100. Op. Cit. 
Em sua Poética do espaço, Bachelard aborda a relação inevitável que existe entre as imagens da infância e as imagens da literatura, ao afirmar que "o conto é a imagem que raciocina" e nos fazendo lembrar o que parece ser a narrativa ancestral desse conceito de miniatura - a história de $O$ Pequeno Polegar. $O$ autor é bastante categórico ao atribuir a esse personagem o poder de revelar uma imagem primordial: "A simples pequenez vai facilitar todas as façanhas"12. Tal conto é encontrado em diferentes culturas e Gaston Paris afirma que aí está "o fundo primitivo de sua história, a marca que se encontra em todos os povos; já as outras histórias que Ihe são atribuídas, criadas pela fantasia que esse serzinho divertido estimula, costumam diferir entre os vários povos". ${ }^{13}$ Deste modo, parece de fato ser um ancestral das aventuras de $A$ Chave do Tamanho, de Monteiro Lobato ${ }^{14}$.

E Bachelard, no mesmo capítulo, apresenta ainda um trecho onde Hermann Hesse se apropria dessa imagem - que é a miniatura - para criar uma fascinante imagem poética:

\begin{abstract}
"Um prisioneiro pintou na parede de sua cela uma paisagem, um trenzinho entrando num túnel. Quando seus carcereiros vieram procurá-lo, ele pediu 'gentilmente que esperassem um momento para que pudesse entrar no trenzinho do meu quadro, a fim de lá verificar alguma coisa. Como de hábito, eles se puseram a rir, pois me consideravam um fraco de espírito. Eu me fiz pequenininho. Entrei em meu quadro, embarquei no trenzinho que se pôs em movimento e desapareceu na escuridão do pequeno túnel. Por instantes, podia-se ver ainda um pouco de fumaça em flocos que saía pelo buraco redondo. Depois essa fumaça se dissipou e com ela o quadro e com o quadro a minha pessoa" ${ }^{15}$.
\end{abstract}

\title{
2.3 Quando o ilustrador lembra-se criança
}

As primeiras imagens dos livros ilustrados para crianças encontram-se na origem do desenho da criança que, por algum motivo, se preserva em alguns sujeitos. Pode-se afirmar que ilustradores da literatura infantil e juvenil são levados pela expressão do desenho que se ramifica em diferentes vertentes, estruturando-se como linguagem em suas gradações mais utilitárias ou mais artísticas.

Essa linguagem, quando se manifesta nos livros ilustrados, traz uma visualidade que tem origens diversas, mas podemos estabelecer dois marcos principais: primeiramente, o imaginário das fábulas e contos de fadas e, posteriormente, o humor e a poesia nonsense que se apresenta na literatura para crianças, mais conscientemente, a partir dos livros Alice no país das maravilhas (1865) e Alice através do espelho (1871), escritos por Lewis Carroll e ilustrados por John Tenniel. A qualidade das imagens de Tenniel vai contribuir significativamente para estabelecer seu aspecto

\footnotetext{
12 BACHELARD. Gaston. Poética do espaço. São Paulo: Martins Fontes, 2008. P.171.

13 Ibidem. P. 172.

${ }^{14}$ LOBATO, Monteiro. A chave do tamanho. São Paulo: Brasiliense, 1997.

${ }^{11}$ HESSE, Hermann. Revista Fontaine, Paris: n.57, P.725.
} 
autoral tendo em vista da extensa lista de citações dessa obra na infinita galeria de permutações, apropriações, recriações, paródias e variações de Alice publicadas até hoje.

No mundo contemporâneo, superpovoado de objetos, as imagens funcionam como signos de informação e sedução, atraindo o observador e dando forma aos conteúdos subjacentes. A ilustração é uma espécie do que Vilém Flusser chama de "pensamento imagético" e dependem de pontos de vista predeterminados, baseados em convenções técnicas e mercadológicas. Por essas características, as imagens dos livros tendem a resignificar imagens do mundo para as crianças, ressaltando um aspecto narrativo da imagem, uma inversão da sua natureza tradicionalmente descritiva. 0 autor afirma que "As imagens da mídia imagética são mais ricas e as mensagens da mídia conceitual (verbal) são mais nítidas." ${ }^{16}$

A exemplo de John Tenniel ao colaborar com o segundo livro de Lewis Carroll, (1871), vemos já uma troca entre a narrativa e ilustração para o desenvolvimento da história. Ao entrar no espelho, Alice se depara com um mundo invertido, e essa fantasia cria vida quando o leitor se depara com as ilustrações. As inúmeras descrições de Carroll do ambiente encontrado por Alice são alimentadas e enriquecidas de detalhes nos desenhos. Porém, as imagens originais de Tenniel oferecem muitas vezes novas camadas de significado em inversões e relações formais internas que, embora possam parecer erros, na verdade, se tornaram parte de um aspecto crucial da estética do livro ilustrado, pertinente ao espaço/tempo.

Perry Nodelman em Words about Pictures: The Narrative Art of Children's Picture Books aponta para dois tipos de ironia da relação entre palavras e imagens no livro ilustrado devido às diferenças inerentes entre a narração verbal e a representação pictórica: "A primeira é a distância entre a objetividade relativa das imagens e a subjetividade relativa das palavras; a segunda é a distância entre o movimento temporal das histórias e a eternidade fixada geralmente nas imagens." ${ }^{17}$ Essa ironia, referida por Nodelman se estabelece pelo jogo entre narração e descrição onde imagens e textos se relacionam cambiando suas características tradicionais para ampliar as possibilidades poéticas do objeto livro.

Assim, a característica da linguagem visual do livro ilustrado para crianças se estabelece a partir do conjunto de imagens que vêm da memória articulada pelo sujeito ilustrador em relação ao texto. A arte de ilustrar se diferencia da linguagem da pintura, uma vez que as imagens se inclinam mais facilmente às verbalizações mentais constituídas pela tendência humana para dar significado àquilo que vemos por meio de uma sequência de imagens. As ilustrações podem se apresentar como uma narrativa independente em nossos livros ilustrados e nos livros de imagem. É o que se costuma descrever como narrativa visual, presente em um ou outro tipo de publicação, e tal função narrativa que a ilustração pode desempenhar já aparece anteriormente nos desenhos de crianças. Desde as garatujas, nos sucedâneos e jogos lúdicos, a "fala egocêntrica" já descrevia cenas e acontecimentos imaginários. Este instrumento do pensamento - a palavra - é indissociável da expressão gráfica.

\footnotetext{
${ }^{16}$ FLUSSER, Vilém. O mundo codificado. São Paulo: Cosacnaify, 2007. P. 115.

17 NODELMAN, Perry. Words about Pictures: The Narrative Art of Children's Picture Books. Apud: LINDEN, Sophie Van der. Para ler o livro ilustrado. São Paulo, Cosac Naify, 2011. P. 165.
} 
Assim, para se compreender a linguagem visual nos livros de literatura infantil e toda sua pluralidade de significados, pode-se igualmente observar o desenvolvimento do grafismo infantil a partir da genealogia do ilustrador. Mesmo adulto, o ilustrador vai até a gênese do seu desenvolvimento como artista e busca lá a comunicabilidade com seu público. Essa possibilidade se dá graças a inextricável relação entre imaginação e memória. Será preciso deixar-se levar para um mundo interno, um mundo de infância, lembrar-se criança.

Bachelard afirma, "Quando na solidão, sonhando mais longamente, vamos para longe do presente reviver os tempos da primeira vida, vários rostos de criança vêm ao nosso encontro". Algumas ilustrações de livros contêm esses devaneios de memória, revelando como realmente os processos verbais e visuais se manifestam numa relação complementaridade, através do diálogo entre interior e exterior. As imagens são, enfim, espacialidades que vêm da memória, enquanto textos são temporalidades imaginativas capazes de deflagrar imagens, tudo de forma cíclica.

Casas, árvores, pássaros, rostos em diversidade: desenhos de criança são únicos quando se permite que ela se expresse livremente.

Desenhos ensinados, ao contrário, são desenhos mortos e ensinar uma criança dos quatro aos nove anos a desenhar é matar a essência de sua expressão, restringindo esse canal comunicativo ao substituir a criatividade pela repetição. Escolas onde se ensinam a desenhar tendem a conduzir os alunos a um processo precoce de generalização, o que se pode notar quando ocorre uma grande semelhança entre os desenhos de diferentes sujeitos de um grupo, seja no modo de configuração ou mesmo no posicionamento de elementos no papel. São desenhos predominantemente comunicativos que nos proporcionam um entendimento imediato, traçados com clareza de formas e com intensidades semelhantes de linhas e cor. Esse direcionamento os torna um tanto previsíveis e, em sua maioria, apresentam poucas soluções criativas.

Opostamente, Luquet (1927) descreve o caso de um garoto belga de três anos e meio chamado Victor que "desenhou no ventre do convidado para o jantar em família, as batatas que ele havia ingerido e representou os botões do sobretudo do visitante que tanto o haviam impressionado contornando toda a figura, num resultado de forte apelo visual". ${ }^{18}$

A ilustração para a criança pretende a mesma aventura do grafismo da criança, pois ambos, cada um ao seu modo, são imagens da infância. Assim como lembrança de rever um lugar ou ouvir uma música não nos traz o mesmo sentimento da primeira vez, a ilustração também perde muito de seu passado, de sua essência infantil. A memória de um prazer é um sentimento do aprendizado, uma revivescência. Por isso, somos às vezes tomados pela nostalgia das primeiras imagens, sem conseguimos ter de volta o frescor daquele momento.

Contudo, neste caso é pertinente apontar a dupla face da experiência estética que muitas outras categorias de imagem podem proporcionar. Esse artigo se refere à ilustração como parte do design e dos livros ilustrados, onde, por um lado é necessário que o sujeito se valha da imaginação em busca de novas sensações estéticas e que o permita lidar com o novo; por outro lado, é a memória que proporciona reviver um

18 DUARTE, Maria Lúcia Batezat. Sobre o sentido das representações gráficas infantis. São Paulo: Unicamp, Anais ANPAP. 1999. 
momento e o imaginário onde se encontram as matrizes da criação de cada autor. Mas existe também outra dimensão da memória que é a História. Ela se torna crucial para a compreensão de como o campo de conhecimento humano estabeleceu suas bases ao longo do tempo, servindo direta ou indiretamente como forma de legitimação e formação de uma linguagem visual específica nas ilustrações de livros. Este é um conhecimento fundamental para a edição dos livros para crianças.

\section{CONCLUSÃO}

Seria difícil encontrar nas ilustrações de livros infantis as marcas de memória ou imaginação que as formularam. Nada pode determinar com clareza essa temporalidade fugidia ou uma causalidade para a forma que essas representações assumem. Nenhuma projeção ou lembrança explícita as explica, a não ser sua referência imediata ao texto que a que ela se refere.

A esse respeito, Gaston Bachelard, em sua fenomenologia das imagens, contradiz o lugar comum ao sugerir que "a imaginação é anterior à memória"19. Não há dúvida que os espaços habitados, observados, percorridos se diferenciam daqueles narrados, descritos, contados. Inconscientemente ou não, parece que a primeira imaginação é iniciada na vivência enquanto a memória passaria reconstruir essas imagens mentais pelo potencial afetivo das marcas dessas vivências no sujeito. Por esse ponto de vista, a palavra, elemento disparador de imagens para o ilustrador de livros, dialoga mais com a memória e as imagens mentais do leitor, e consequentemente do ilustrador, do que o mundo presente que o rodeia. A ilustração de literatura infantil não representa o mundo, mas constrói metáforas ou a ressignificação das imagens a partir da memória.

Talvez, por ter ainda uma vivência limitada de passado, o mundo presente toca a criança mais diretamente. Bachelard afirma que ao desenhar a casa, a criança irá revelar o sonho mais profundo em que ela deseja abrigar sua felicidade e que as marcas dessa felicidade são visíveis no desenho, pois "toda grande imagem simples revela um estado de alma". A casa, mesmo reproduzida em seu aspecto exterior, fala de uma intimidade, ou seja: "Quando a criança é feliz a fumaça brinca delicadamente acima do telhado. Se a criança é infeliz, a casa traz a marca das angústias do desenhista". ${ }^{20}$

Por esse ponto de vista, podemos concluir que as possíveis marcas da infância sobre a ilustração seriam o próprio ato de desenhar. Não há mais registros dessa felicidade na "caligrafia" que o gesto espontâneo deixa a mostra, nem na forma dos objetos ou em um detalhe significativo como uma porta aberta por onde se pode entrar, conhecer, decifrar. A ilustração pretende imitar superficialmente esse estado de espontaneidade, o ilustrador quer dar um corpo concreto a uma frase, quando o faz com competência, transforma sua impressão em uma metáfora visual ou refaz o caminho que o texto descreve com novos significados. Já no desenho de criança encontramos o mundo sem disfarces, o mundo como imagem, obra da imaginação absoluta onde a criança extrai todo o seu ser da imaginação.

\footnotetext{
${ }^{19}$ BACHELARD, Gaston. 2008. P. 131. Op.Cit.

${ }^{20}$ Ibidem. P. 85.
} 
O ilustrador de livros coleciona desde sempre as imagens da infância, essas imagens moldaram seu traço, seu mundo interno é povoado de memórias e ele as revive a cada texto no potencial imaginativo que ficou guardado dessa fase de sua vida.

$O$ desenho de criança e o desenho para criança se encontram na memória.

\section{REFERÊNCIAS}

ALENCAR, J. Salmo Dansa de - O começo é o fim pelo avesso: a transposição da narrativa oral para o desenho infantil. 95 f. Dissertação (mestrado) - Departamento de Artes e Design - Pontifícia Universidade Católica do Rio de Janeiro. RJ, 2004.

BACHELARD, Gaston - Poética do espaço. São Paulo: Martins Fontes, 2008.

- Poética do devaneio. São Paulo: Martins Fontes, 2009.

CARROLL, Lewis - Alice: edição comentada. Rio de Janeiro: Jorge Zahar Ed., 2002.

DARRAS, Bernard - Au commencement était l'image. Du dessin de l'enfant à la communication de l'adulte. Paris: ESF éditeur, 1996.

DUARTE, Maria Lúcia Batezat - Sobre o sentido das representações gráficas infantis. São Paulo: Unicamp, Anais ANPAP. 1999.

DURAND, Gilbert - O imaginário. Rio de Janeiro: Difel, 1994

EDWARDS, Beth - Desenhando com o lado direito do cérebro. Rio de Janeiro: Ediouro. 2000.

FLUSSER, Vilém - Filosofia da Caixa Preta. Rio de Janeiro: Relume Dumara, 2002

- Mundo Codificado - Por uma filosofia do design e da comunicação. São

Paulo: Cosac Naify, 2007.

LINDEN, Sophie Van der - Para ler o livro ilustrado. São Paulo, Cosac Naify, 2011.

LUQUET, George-Henri. (1927) - O desenho infantil. Porto: Ed. Minho, 1969.

MUNARI, Bruno - Livros para crianças. In: MUNARI, Bruno. A arte como ofício. Lisboa:

Presença, 1987.

PIAGET, Jean.; INHELDER, B. - A psicologia da criança. Rio de Janeiro. São Paulo: Difel, 1968.

SCHWARCZ, Joseph. H. - The Ways of the Illustrator. Chicago: American Library Association. 1982.

José Salmo Dansa de Alencar - Doutorando PUC-Rio - Bolsista Capes

salmo.dansa@gmail.com

Orientador: Prof. Dr. Luiz Antonio Luzio Coelho 